\title{
Climate-Smart Agriculture: Soil Health \& Carbon Farming
}

This fact sheet is the first installment of a four-part climate-smart agriculture series exploring the relationship between carbon farming, soil health, and soil amendments on CA croplands and rangelands. Subsequent fact sheets will address the benefits of compost, pulverized rock, and biochar as amendments. The series is intended for members of the technical assistance community who advise CA growers on climate-smart agriculture.

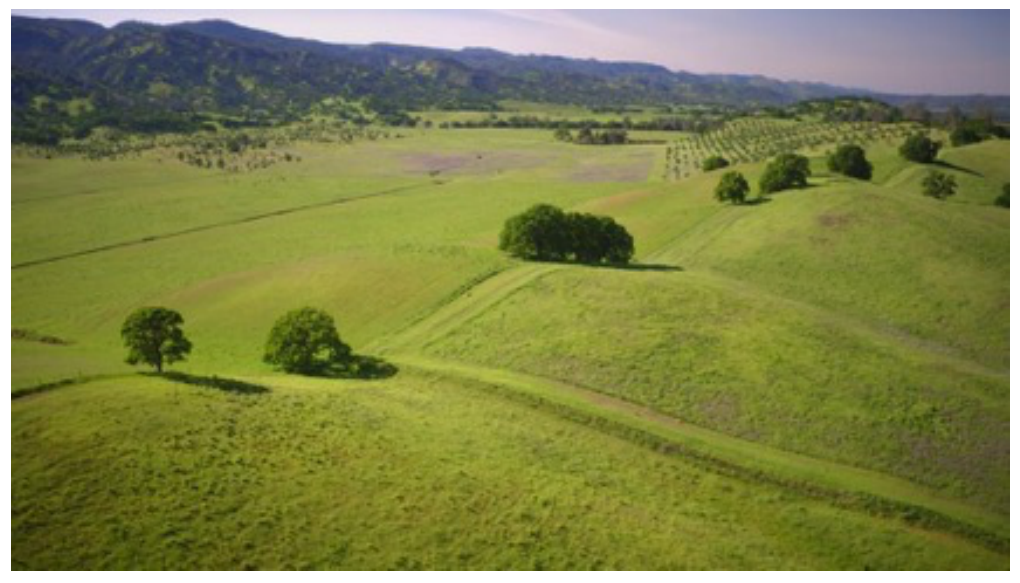

Image: Joe Proudman, UC Davis 2019

\section{What is carbon farming?}

Carbon farming is the use of specific on-farm practices designed to take carbon out of the air and store it in soils and plant material. Carbon farming practices include application of soil amendments like compost or biochar, conservation tillage, agroforestry, whole orchard recycling, cover crops that maximize living roots, and many others. (See USDA-NRCS Soil Health Management to access the Greenhouse Gas and Carbon Sequestration Ranking Tool for Agriculture)

\section{Is carbon farming a way to address climate change?}

Building soil organic matter on croplands and rangelands sequesters carbon in soils, which helps mitigate the effects of climate change while potentially providing co-benefits for soil health and increased adaptive capacity. Soil amendments may increase the amount of carbon held in soil organic matter, leading to greater carbon sequestration. Practices that increase carbon storage in soils and divert waste (such as compost creation from food and animal waste) can help California meet its goal of carbon neutrality by 2045. It is estimated that over 25 million metric tons of $\mathrm{CO}_{2}$ can be sequestered annually on natural and working lands in California by 2045. ${ }^{1}$ For reference, 1 million metric tons is equivalent to removing over 215,000 cars from the road each year.

\section{What do we know about the science of soil amendments?}

The Working Lands Innovation Center is testing the carbon sequestration potential of compost, biochar, and pulverized rock amendments and calculating the cobenefits for crop and forage yields, soil health, fertility, and water storage capacity. This work will contribute to the growing knowledge of carbon farming and provide resources to aid the technical assistance community in advising growers on practical application. Carbon Cycle Institute and its partners have developed a Carbon Farm Planning framework that is based on NRCS practice standards. The framework is currently applied by over 35 Resource Conservation Districts across the state to aid producers in the planning process. The figure to the right shows how compost, biochar, and rock amendments may lead to enhanced carbon sequestration in soils.
Without soil amendments

With soil amendments

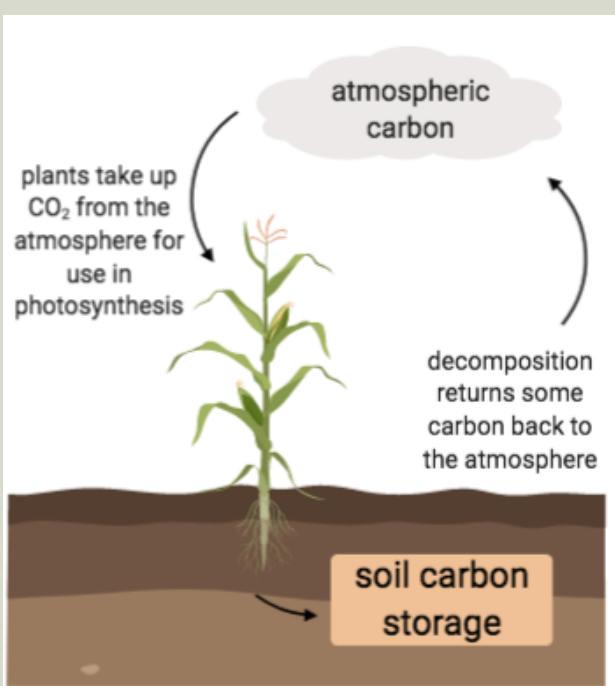

soils hold varying levels of soil organic carbon in soil aggregates, roots, and soil life

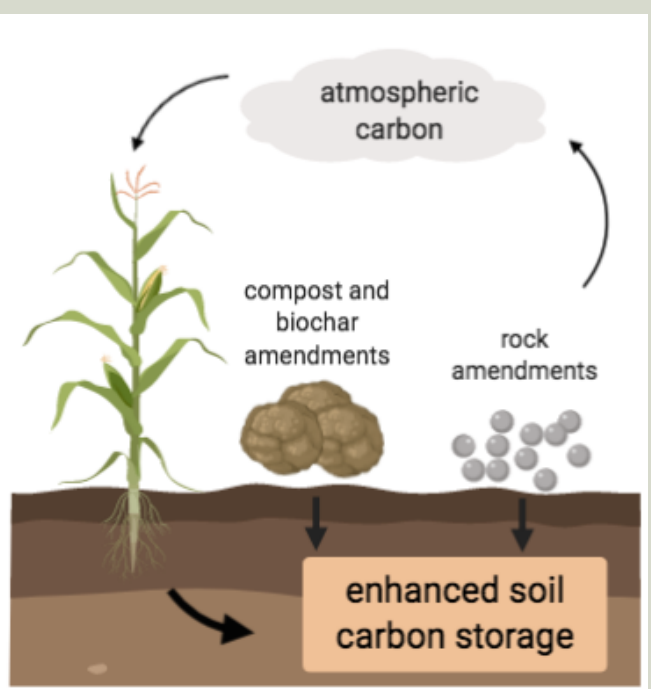

soil amendments may lead to increased soil organic carbon, leading to carbon sequestration and enhanced soil health 


\section{How does climate-smart ag relate to soil health and resilient farms?}

Many of the same practices that sequester carbon in the soil can improve soil health on agricultural lands. Some amendments such as compost and biochar may improve soil structure, which promotes long-term soil health and productivity of the land. Amendments that increase soil organic matter may improve the water holding capacity and infiltration in soils, which promotes resilience to climate-related impacts such as drought, heat waves, or heavy rains. Additionally, research shows that amendments can promote biological activity and supply vital nutrients, resulting in healthier plants that are less vulnerable to pests and disease.

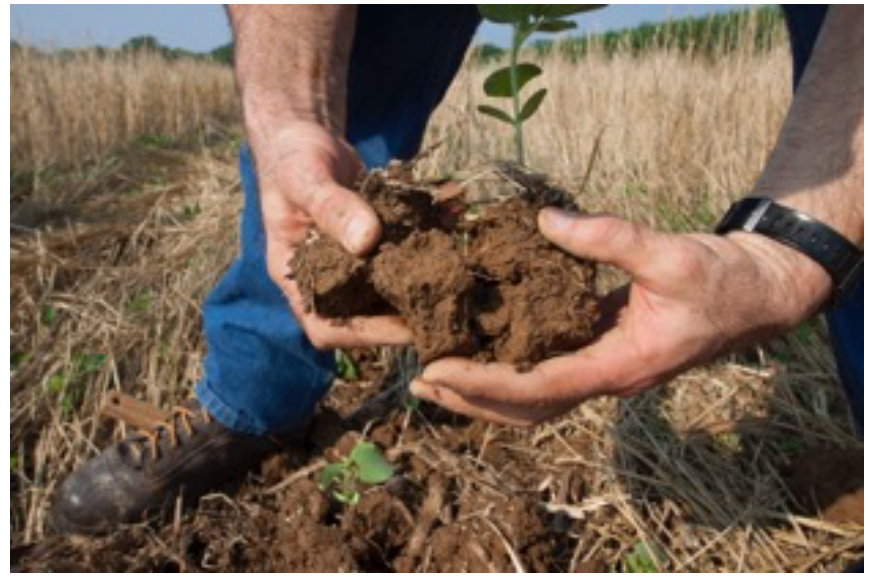

Image: Lynda Richardson, NRCS Photo library

\section{What are the benefits to growers?}

Soil amendment applications benefit growers by increasing agricultural productivity and supporting outcomes that enhance resilience to climate-related impacts. Benefits of amendments can potentially include:

- Increased nutrient availability and retention due to increased soil organic matter ${ }^{2}$

- Increased crop and forage yields ${ }^{3}$

- Increased water holding capacity and water infiltration in soils ${ }^{4}$
- $\quad$ Enhanced microbial activity in soils 5

- $\quad$ Improved crop quality ${ }^{6}$

- $\quad$ Reduced need for chemical fertilizers

- More resilient soils

- More sustainable agricultural systems

Growers who implement carbon farming practices may be more competitive with consumers, or eligible for carbonbased farming incentives.

\section{Where can growers find more information?}

$>\quad$ UC Davis Soil Health Portal, information on soil organic matter here

$>\quad$ FAO Soils Bulletin, soil organic matter here

$>\quad$ UC ANR Solution Center for Nutrient Management, compost here

$>\quad$ Carbon Cycle Institute, information on carbon farming here

$>\quad$ USDA California Climate Hub website here
The Working Lands Innovation Center (WLIC) aims to catalyze negative carbon emissions by deploying soil amendment technologies at multi-acre scales in partnership with California researchers, state agencies, industry, farmers, ranchers, Tribes and smallbusiness development. See their website.

1. Baker, S. E., et al. (2020). Lawrence Livermore National Laboratory, LLNL-TR-796100. Retrieved from https://wwwgs.IInl.gov/content/assets/docs/energy/Getting_to_Neutral.pdf

2. Sustainable Agriculture Research \& Education. (2012). Organic Matter and Nutrient Availability. Retrieved from https://www.sare.org/Learning-Center/Books/Building-Soils-for-Better-Crops-3rd-Edition/Text-Version/Nutrient-Management-AnIntroduction/Organic-Matter-and-Nutrient-Availability

3. Gravuer, K., et al. (2019). Global change biology, 25(3), pp.1152-1170. doi:10.1111/gcb.14535; Oldfield, E. E., et al. (2019). Soil, 5(1), 15-32. doi:10.5194/soil-5-15-2019

4. Lepsch, H. C., et al. (2019). Agricultural Water Management, 222, 204-212. doi:10.1016/j.agwat.2019.06.002

5. Ros, M., et al. (2006). Soil Use and Management, 22(2), 209-218. doi:10.1111/j.1475-2743.2006.00027.x

6. Abawi, G., et al. (2000). Applied Soil Ecology, 15(1), 37-47. doi:10.1016/s0929-1393(00)00070-6

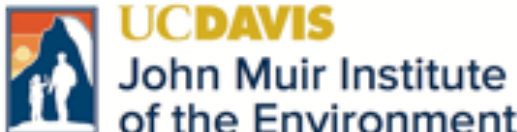

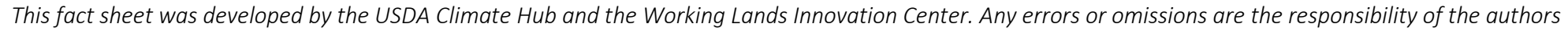

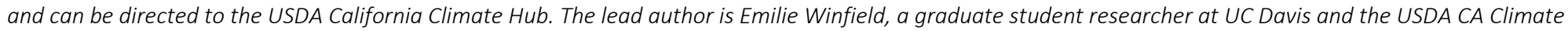

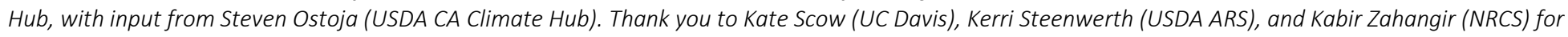
serving as reviewers. For fact sheets on other topics related to CA agriculture, please visit https://www.climatehubs. usda.gov/hubs/California. 